\title{
STATUS OF REMOTE SENSING TECHNIQUES IN NATURAL RESOURCES PLANNING AND SUSTAINABLE DEVELOPMENT IN NIGERIA
}

\author{
Aladelokun, Adeniji Olawale (Ph.D) \\ Department of Spatial and Planning Sciences, Bamidele Olumilua University of Education, \\ Science and Technology, Ikere - Ekiti, Ekiti State, Nigeria.
}

Article DOI: https://doi.org/10.36713/epra7927 DOI No: 10.36713/epra7927

\begin{abstract}
There is the palpable inadequacy of scientific data gathering in Nigeria despite the urgent needs for such in proper environmental assessment and management. This paper, however, investigated the status of remote sensing in Nigeria and its potentialities in helping to solve the problems of natural resources planning and management for sustainable development. Primary and secondary data are basically the sources of information. Be that as it may, it is discovered that remote sensing technique has been useful in data gathering for planning and monitoring of environmental resources. Meanwhile, strategies to improving its usage as scientific tool for data gathering for developmental projects in Nigeria are suggested.
\end{abstract}

KEY WORDS: Development, Natural Resources, Planning, Remote Sensing, Sustainability

\section{INTRODUCTION}

The development of remote sensing technology has offered an opportunity that many and diverse research efforts have been made possible and along inter-disciplinary lines. It has developed so quickly and has outstripped the conventional system of data collection for environmental assessment and monitoring (Melesse \& Wang, 2007). The benefits of remote sensing are articulated. These include among others: increasing data capture in terms of space; time and radiance; homogeneity data; spatially continue data; and suitability of data for computer processing and as well as the potential for revolutionizing the detection and characterization of many phenomena (Curran, 1992).

Remote sensing is concerned as the noncontact recording and acquisition of information of some properties of an object or phenomenon from the region of electromagnetic spectrum through the use of instrument (e.g. camera, radiometer, scanners and radar) located in a motioned platform (aircraft or space-craft). In other words, it is seen as the joint effects of employing modern sensors data-processing equipment, information theory and devices, space and airborne vehicles and large-systems theory and practice for the purpose of carrying out aerial or space surveys of the earth's surface (Harris, 1987; Curran, 1992; and Okhimamhe, 1993). It is a potential tool to study change in land cover, forest density, coastal morphology, status of reef and biodiversity of Islands even if located in remote place (Kumar, et. al., 2015).

There are different types of remote sensing techniques, some of which are photographic. Photographic remote sensing involves the panchromatic and infra-red bands of the electromagnetic spectrum. Those are concerned basically with detecting reflected radiation either from visible or non-visible bands of the spectrum. The non-photographic remote sensing imagery technologies have been developed to detect potential sources of data through interpretation of photographed materials. Those sensors include those that operate in the thermal infrared ultra-violet fluorescence and gamma ray detectors while microwave sensing is both passive and active. The type is radar. Some of these are concerned with separate techniques for exploration (Akinboye, 1996). 
Essentially, remote sensing operates on two distinct platforms viz: ground platform which is concerned with low altitude, and the air platform which has to do with both low and high altitude. However, Areola, (1986) stresses that three major remote sensing systems have been developed. These are the camera or photographic system; the thermal or scanning system; and the radar or micro-wave system. The camera or photographic system records only reflected energy usually between 0.4 and 0.7 micrometres on the electromagnetic spectrum. On the other hand, both the thermal and radar systems are more technologically advanced system of remote sensing and have been designed to further enhance the effectiveness of aerial photograph through the provision of more and clearer views of the earth with a view to monitoring its features and resources. However, since no simple remote sensing technique can provide an adequate view of the earth, there has been an attempt to integrate all remote sensing techniques into one multi-stage multiple technique that will facilitates large-scale data collection and analysis (Akinboye, 1996).

\section{THE PROBLEM}

In spite of the phenomenal growth and achievements of remote sensing over the orthodox/conventional method of data collection in the development of any nation, especially in the area of planning and resources management, it is highly observed that rising public expenditure on the technique has not really translated to its meaningful utilization in addressing environmental and developmental issues as Nigeria is still ranked among world's poorest countries. There are many situations in which a better data would improve our ability to assess our resources, make use of them, and understand our environment. For instance, the population explosion, although no longer new, deserves to be monitored. People with unprecedented number will be fed, clothed, and housed. In fact, they will demand more than these - method, policies and monitoring procedures already are inadequate locally and naturally. With the number that are in prospect; it will not be enough simply to do better what we have been doing (Rudd, 1974).

Apart from number, it is observed that the rising standard of living that all people want to experience will require more of everything per person. The requisite technology to satisfy such needs and numbers would make the ecological impact we have observed to date pale by compassion. Again there is the accelerated rate of change with which things can happen now. Our capability to modifying the earth's surface has so increased that landscapes can be changed overnight. When changes are so rapid, so extensive and so numerous that their cumulative effects can produce unforeseen results, the kind of monitoring which has served in the past will no longer suffice.

Therefore, we are going to need (if indeed we do not already) qualities and types of information here that are unimagined. If we are to have an adequate appraisal of our resources on which to base plans for more ordered use, if we are to be able to foresee incipient problems soon enough to make remedied action worthwhile, and if we wish to understand the natural environment well enough to be able to prepare for or modify its diverse moods, we must improve our ability to collect information(Rudd, 1974).Similarly, Areola (1986) expressed his disappointment on the very weak process of gathering data in Nigeria. He stressed that Nigeria is facing serious challenges in the field of planning and resource management resulting from inadequate scientific data collection. He, however, suggested that there is the need to develop a supper capability in remote sensing and so to develop a reliable data gathering storage and retrieval system in Nigeria.

\section{OBJECTIVES}

It is the realisation of the above stated problems that this study now sets to investigate the status of remote sensing as a scientific technique that could be used to surmount the challenges facing natural resources planning and sustainable development in Nigeria and to highlight various strategies to improve the use of the technology for better environmental resources management with a view to assist in country planning as well as controlling environmental hazards.

It is believed that this article will be of immense use to the entire nation as it would provide a framework upon which local, states and federal government as well as planners and individuals can build upon and expand to alleviate the ever increasing problems of environmental resources management in Nigeria.

\section{METHODOLOGY}

Both primary and secondary information were sort for this work. The primary data constitutes information collected from well learned persons from tertiary institutions of learning and some officials of remote sensing centres in Nigeria. This information together with the secondary data from library and other relevant publications were considered and discussed.

\section{STATUS OF REMOTE SENSING IN NIGERIA}

The growth of remote sensing like any other discipline tends to follow a sigmoid or logistic curve. Based on the words of Curran (1992), four distinct stages of the technique's growth are identified. Stage one is a primary growth period with small absolute 
 \\ EPRA International Journal of Research and Development (IJRD)}

increments of literature and little or no social organisation. Stage two is a period of exponential growth when the number of publications double at regular intervals and specialist research units are established. Stage three is a period when the growth rate decline and although the annual increments remain constant, specialisation and controversy increase. Stage four is final period with the rate of growth approaches zero, the subject reaches maturity. It is interesting, however, to know that many efforts have been put in place to ensure the utilisation of this darling and efficient technique in exploration of the diverse environmental resources of the nation. The knowledge from this frame work, therefore, indicates that Nigeria is struggling hard to survive the third stage of the growth. For instance, Nigeria can now boast of some remote sensing centers within the country such as the National Center for Remote Sensing /Orbital System (NCRS); Nigerian National Space Research and Development Agency (NASRDA); Nigeria Regional Support Office/UNSPIDER Knowledge Portal; National Centre for Remote Sensing, Jos; Nigeria, National Centre for Remote Sensing, Department of de Beron; National Aeronautics and Space Administration (NASA), etc.

According to Way (2020), Nigeria's space goals stemmed from a reaction to a military regime from 1993 to 1998 led by General Sani Abacha. An administration noted for its aversion to intellectual inquiry. His successor, former President Olusegun Obasanjo strongly advocated for Nigeria's futureto be beyond our planet, and in space. Therefore, in 1999 the National Space Research and Development Agency (NASRDA) was formed to pursue formalised space projects. In 2003, Nigeria procured the launch of its satellite - NieriaSat-1, an Earth observation satellite that became part of the international Disaster Monitoring Constellation (DMC). A total of five satellites have been launched since then, with three still operational as of 2020. The current government led by President Muhammadu Buhari is highly supportive of the Nigerian space program.

In 2005, NASRDA unveiled a radical plan for its future. However, its progress is currently not on track with what NASRDA had envisioned. In 2005, Nigeria stated its main goals which were to: manufacture a Nigerian satellite; have a Nigerian astronaut; and create a Nigerian launch vehicle to launch Nigerian-made satellites from a spaceport located in Nigeria. As of today, however, there are no Nigerian astronauts or training programs, and the only goal that has been accomplished has been the manufacturing of a Nigerian satellite. In a 2016 article by CNN, Calestous Juma, a specialist on space programs in developing countries at the Harvard Kennedy School, suggests the mission to send a Nigerian to space on a Nigerian-built rocket represents a "lofty ambition." Juma continues to note that he believes the vision of Nigerian space exploration is more important than meeting the deadlines (Way, 2020).

Outside of these stated formal goals, the implicit objective for the program has been to aid in the socioeconomic development of the Nigerian people through investment in science, technology, engineering, and mathematics (STEM) education and earth observation technology. Nigeria intends to utilize these future technologies to help fight climate change, aid in agriculture, tackle Boko Haram, and combat the issue of piracy in the Gulf of Guinea. The goals of NASRDA align well with the stated goals of the Nigerian government to work towards attaining the United Nations' Sustainable Development Goals (SDGs)(Way, 2020).

Meanwhile, SPORT and LANDSAT panchromatic imageries as well as Aerial photography interpretation have assisted in advancing knowledge significantly in a number of disciplines such as Agriculture, Environmental monitoring, Forestry, etc. In other words, increasing emphasis on the utility of employing remote sensing platform to obtain real time assessment of agricultural landscape, environmental issues, distribution and utilization of natural resources, border and military surveillance, etc. cannot be over emphasized. For instance, precision agriculture is a production system that promotes variable management practices within a field, based on site conditions. This system according to Seelan et. al. (2003) as reported by Kumar, et. al. (2015) is based on new tools and sources of information provided by modern technologies including remote sensing.

Report on a study of the benefits of precision agriculture in Nigeria by Abdulwaheed (2010) carried out in National Centre for Agricultural Mechanization (NCAM) situated at Ifelodun Local Government Area of Kwara State, Nigeria reveals that Satellite Remote Sensing is helping to bring agriculture in Nigeria into digital age. With the latest take-off of the NigeriaSat-1, an earth observing satellite for the meteorological, natural resources, hazard observation and management purposes, Nigeria now joins the league of nations that have access to the opportunities afforded by Satellite Remote Sensing in revolutionizing their agriculture. The market for precision farming, therefore, is of significant economic importance and offers great opportunities for local farmers in both 'pre and post' farming seasons. Today, farmers in Nigeria have access to a wealth of information, so much that they do not know what to do with it. However, it is a thing of joy to note that the new technology in place has the capability of analyzing huge amounts of data in a short period and using it to suggest the best course of 


\section{EPRA International Journal of Research and Development (IJRD)}

action. This information could then be used to predict best time to plant, the outbreaks of pests and disease before they occur, and to offer in-field inventory management that could offer yield predictions prior to harvest.

Water as a resource is essential to support human existence. The availability of fresh water for human use has been declining over the years, whereas the demand of growing population is increasing. In this context, there is an urgent need to monitor and obtain a better understanding of its use., which will provide information that can assist towards the development of effective water management strategies and infrastructures. This can be of crucial importance, particularly to regions on which the amount of water available is limited (Kumar, 2015). Understanding the complex water system requires a holistic approach to integrate the concepts and ideas from different disciplines for sustainable water resource management. A field scale study brings first insights to develop a detailed understanding about the manifold processes of the water cycle. However, the political decisions are made at regional to national level and thus it is crucial to reasonably upscale field scale studies to regional national level. Hydrological models are generally used for this purpose but often suffer problems of data scarcity or lack of quality input data. Remote sensing technologies would then be a promising tool to integrate with the models for getting continuous input data in data scarce regions. The launch of several Earth Observation (EO) sensors from advanced satellites provides world-wide continuous measurements on various hydrological components which are essential input data for hydrological modeling. The data gaps due to lack of on-the-ground monitoring of water resources around the world are now available using satellite acquisition. Thus, satellite products and sophisticated computational techniques for the management of water can play an important role in the present and future of water resources. The satellite remote sensing for hydrological applications includes but not limited to rainfall (Global Precipitation Measurements (GPM) and Tropical Rainfall Measuring Mission); Soil moisture (Soil Moisture Active Passive (SMAP) and Soil Moisture Ocean Salinity (SMOS); Actual Evapotranspiration (Surface Energy Balance Algorithm for Land (SEBAL); Groundwater level monitoring by Gravity Recovery and Climate Experiment (GRACE) (Bastiaanssen et. al., 1998; Liu, 2021; Sun, 2013).

Meanwhile, a recent study carried out by Adebola et. al. (2017) employed Remote sensing (Landsat imagery from 1987 to 2016) and GIS to determine shoreline and surface water quality changes in Bayelsa State, Nigeria. Supervised classification, object-based image analysis, shoreline extraction and image enhancement processing techniques were adopted. The data obtained was analyzed and maps were generated and then integrated in a GIS environment. The results indicate that Land-use land-cover (LULC) changes in wetland areas increases rapidly during the years (1987-2016) from $34.83 \%$ to $38.96 \%$. Polluted surface water was observed to have decreased from $30 \%$ to $20 \%$ during 1984-2010 and reduced by about $3 \%$ in 2016. In addition, the result reveals the highest level of erosion from 1987 to 2016 which is $-49.60 \%$ against the highest level of accretion of $13.39 \%$ EPR and NSM -1400 erosion against 350 accretions. It was also observed that variations in shoreline changes affect the quality of surface water possibly due to shoreline movement hinterland. This study has demonstrated that through Satellite Remote Sensing and GIs techniques, the Nigerian coastline can adequately be monitored for various changes that have place over the years.

Forest is an ecosystem where the predominant vegetation is made up of trees and shrubs. Forest resources play crucial roles in the provision of food, shelter, wildlife habitat, fuel, daily supplies of medical ingredients and paper. The role of forest is manifold especially in climate change as it acts as a cause and as a solution for greenhouse gas emissions. However, forests are dynamic in nature and mostly affected by many coexisting processes such as deforestation, urbanization and wild fire. In other words, forests are becoming great victims of civilization as the global population has been increasing, with the consequent problems of deforestation, contamination, and use. For the conservation of the forest, therefore, it is necessary to stop the loss and degradation of forest ecosystems and promote their restoration. More so, that it has the potentialities of contributing more than a third of the total mitigation of climate change, which is necessary to meet the objectives of the Paris Agreement by 2030 (Abad-Segura, et. al., 2020). It is worthy to note that should ecosystem stop to provide their services; the alternatives would be costly. In this way, the need arises to implement new approaches and tools for study and conservation, using remote sensing. Current scientific advancement in remote sensing application in forestry has led to more reliable procedures for monitoring forest resources. Beside aerial photography, other systems such as radar, LiDAR, thermography and optical sensors provide cost-effective methods of spatial data collection for forest monitoring and management.

Usman et. al. (2020) conducted a study of forest resources management of Northern Nigeria using geospatial tools. The study investigated the reliability of Remote Sensing (RS) and Geographical 
Information System (GIS) in monitoring and management of vegetation resources for sustainable development. Landsat MSS satellite images, Landsat Operational land imager and field survey were used in the study. The result shows that in the study area, vegetation resource, mainly woodland, is on the decreasing trend at the rate of $15.59 \%$ while crop/bare lands increases by about 50\%.By implication, the rapidly declining vegetation resource in the study area requires urgent attention. Meanwhile, the result further reveals that modern technologies such as satellite Remote Sensing (RS) and Geographical Information System (GIS) are capable to be used to surmount the problems associated with the changes that occur on vegetation resources in the nation.

According to Kumar (2015), extensive multi-temporal spatial data is required for the management of natural disasters such as flooding, earthquakes, volcanic eruptions and landslides. In this context satellite remote sensing is an ideal tool that offers information over large areas and at short time intervals, which can be utilized in various phases of disaster management, such as prevention, preparedness, relief, reconstruction, early warning and monitoring. The activation of the International Chapter "Space and Major Disasters" (ICSMD) in Nigeria is a relatively new concept to disaster management in the country. The activation of the ICSMD involves collaboration between the National Emergency Management Authority (NEMA), the National Space Research and Development Agency (NASRDA) and the Regional Centre for Training in Aerospace Survey (RECTAS). Between 2010 and 2012, the ICSMD was activated by NEMA for floods in Sokoto, Ibadan, Adamawa, Kogi and Bayelsa. The results from these activations have enhanced the ability of NEMA to respond to disasters swiftly and efficiently. These activations as well complimented the Nigerian satellite infrastructures - Nigeriasat - 1, Nigeriasat -2 , and Nigeriasat $-X$ (Okolie, 2016). Challenges facing remote sensing in Nigeria

Meanwhile, the consideration for increased monitoring and assessment of environmental resources like climate monitoring of desertification in the North,agricultural planning in the Niger Delta, etc. for sustainable socioeconomic development has made investment in space become integral part of plans for Nigeria. However, this step has been hacked by significant political, social, technical, and economic challenges that would be necessarily required to be surmounted should Nigeria thriving space program be developed.

Corruption was really a huge issue within the military dictatorship of the late $20^{\text {th }}$ century in Nigeria. Nigeria is relatively a young democratic nation, such that it faces unique challenges of recovering from its past. For instance, to combat corruption in its space program, NASRDA was built with anti-corruption measures including, that no person convicted of corruption shall be able to hold any high level office in the country. It is disheartening to know, that this policy is witnessing an historically low rate of corruption prosecutions. The present administration led by President Muhammadu Buhari cracked down on corruption, but this has been faced with critism of investigating his rivals and exonerating his friends especially his political affiliates. The Nigerian space agency is considered prime example of bureautic corruption' that is large amount of money is going to organizations that have little or no direct impact in the lives of Nigerians (Way, 2020).

Looking at world corruption lists, corruption in Nigeria is somewhat ubiquities. Nigeria was ranked 144 out of 180 countries listed in 2018 (Transparency International's Corruption Perception Index (CPI, 2018). Without improving measures to combat corruption, the space agency risks losing its credibility as organization committed to combating corruption. Therefore, addressing this issue within the government and the Nigerian space community becomes necessary to establish public trust in the government's space goals.

No doubt, the goal to have domestic capacities is admirable, but Nigeria may be missing out on a large opportunity to take advantage of falling launch costs. Currently, Nigeria does not have any launch system in development. Chinese and Russian rockets are relied on to launch its satellites into orbit. For instance, in 2018 Nigeria agreed to give a $\$ 550$, million equity stake in the state-owned satellite operator NigComsat to a Chinese satellite company, China Great Wall to manufacture two communication satellites to be launched by China two years after the final agreement is signed. China Great Wall now owns to close to 50 percent equity in Nigerian government owned satellite operator. This has increased the reliance on Chinese funding and technology for its satellite program. It is, therefore, required that Nigeria government provides capacity training for its engineers so that they could learn how to construct and design satellites.

Based on the words of Way (2020), oil is the backbone of the Nigerian economy. Owing to lack of diversity in the exports of Nigeria, the success or failure of the Nigerian economy is intimately linked to oil. However, with a growing global emphasis on emphasis on renewable energy, Nigeria should look into diversifying its economy to further ensure it can thrive. Already, the country is making great strides to do so, through increasing infrastructure spending, agriculture, agro-based industry, innovation, and STEM industries - including space. 


\section{EPRA International Journal of Research and Development (IJRD)}

A majority of Nigeria's budgeted money for space goes to its civil space agency, NASRDA. As of December, 2019, the government approved a budget for space that is nearly 20 percent of the total budget for Ministry of Science and Technology. The 2020 budget allocates $\$ 59.26$ million (USD) for space activities in Nigeria. NASRDA was given $\$ 44.18$ million, which is roughly 75 percent of the total budget for space. NigComsat, the Nigerian state-owned satellite operator, was allocated \$9.54million, roughly 16 percent. The Defense Space Administration which focuses on military application for space received $9 \%$ of the total budget for space, totaling to $\$ 5.48$ million. The majority of fund, going to the civil agency of Nigeria indicates the government's commitment to civil operations, such as weather monitoring and climate change research and mitigation. No doubt, the financial impact inflicted by COVID - 19 has really caused set back on some of these projects.

However, in a recent publication of the Nigerian News of $7^{\text {th }}$ June, 2021, the Director General of the National Space Research and Development Agency (NASRDA) Dr. Halilu Shaba revealed that Nigeria Satellite which was last licensed in 2011 has expired and that it is now functioning based on 'Grace'. In other words, the Satellite licensed to function for only seven years has expired in 2018 but by special 'Grace', it is still giving us necessary data. By implication, it may stop functioning any moment from now if nothing is done urgently to keep it going. This will result to stoppage of security information as well as stoppage of revenue coming to coffer of the government through such data.

\section{CONCLUSION}

Remote sensing is a reality whose time has come. It is too powerful a tool to be ignored for terms of both its information potential and logic implicit in the reasoning processes employed to analyze data. It is believed that it would change our perception, our method of data analysis and models and our paradigms. The broader view of remote sensing will be needed not only for what additional information it will provide about the known, but especially for its probable application to presently known but sure-tobe very sophisticated future problems. The more capable view should provide a good forum for making future decisions.

Finally, remote sensing is of tremendous significance in communicating processes including space probe, distribution and utilization of natural resources like vegetation. However, remote sensing should not be seen as a panacea, but simply as an additional but very powerful tool to be added to those which already are in use. It will not provide the solution to problems, but it can provide the basic information necessary for arriving at solution, hence, the necessity in environmental assessment.

\section{RECOMMENDATIONS}

The ultimate goal of remote sensing in any nation is to reach the stage of maturity when reliable information can as a matter of routine be generated for the proper management of our fragile environment. However, the realization of poor application of this noble modern tool in the country has called for the advancement of the following strategies as means of improving on its utilization especially in environmental resources monitoring.

i. Consideration must be given to openness of remote sensing policies and legislation as regards to remote sensing data. The most pressing problem facing remote sensing is the legal right to territorial sovereignty of each other states. It is, however, considered under international law of a nation to trespass on another nation's outer space. This must be replaced since every other state or nation can always benefit from the attendant products. The low status of remote sensing in Nigeria, however, calls for the awareness of this noble vehicle for data collection nation-wide through media, public lectures, and other viable channels.

ii. Priority for data acquisition by the government and interested individual organization should be encouraged. Since there are limited centers in the country, each state should be encouraged to have her own receiving center, as well as ensuring that the existing ones at strategic places in the country are well equipped.

iii. Prompt dissemination of environmentally transient data to places or states that require them should be done. No information should be treated as so sensitive to the extent of keeping it out of reach of others. Sharing data at local, state and national levels should be handled seriously to solving environmental problems such as desertification, water pollution, flooding, etc.

iv. There should be an increase in education and training in remote sensing which is desirable at both introductory and advance levels. Less than one tenth of the universities in the country have remote sensing as part of their courses of study and where it is being studied, the available facilities are grossly inadequate. No incentive is available for students undertaken the course as it is done in other courses like fishery, agriculture, law, survey, and most of the engineering courses. Remote sensing is a sensitive technology requiring trained personnel their effective exploration. Training is, therefore, a prerequisite not only to begin using the 


\section{EPRA International Journal of Research and Development (IJRD)}

technology but also to keep up with rapid advancement in their development.

Be that as it may, adopting the solutions advanced above would go in no small way to alleviating the present predicaments facing the use of remote sensing as a data gathering tool in monitoring and better planning of the natural resources for sustainable development in Nigeria.

\section{REFERENCES}

1. Abad-Segura, E., Gonzalez-Zamar, M. D., Vazquez-Cano, E., \& Lopez-Meneses, E., (2020). Remote sensing applied in forest management to optimize ecosystem services: Advances in research. Forest. 11, 1-28.

2. Abdulwaheed, A. (2010). Benefit of precision agriculture in Nigeria. London Journal of Research in Science: Natural and Formal. 19(2). 27-34

3. Adebola, A. O., Ogunnnibido, T. H. T., Adegboye, S. A., Ibitoye, M.O., \& Adeseko, A. A. (2017). Remote sensing and gis application in determining shoreline and surface water quality changes in Bayelsa State, Nigeria. Ethiopian Journal of Environmental Studies and Management 15(5), 11-18

4. Adefolalu, D.O. (1986). Regional studies with satellite data in Africa on desertification of the Sudan Sahel both in Nigeria. In Erofe, C. (ed) Pro ISLSCP, Conf.Pgs 429-439. Rome, Italy.

5. Akinboye, A. (1996). Research methods in Geography. Ekpoma, Edo State University Publishing House.

6. Areola, O. (1986). Introducing remote sensing techniques in routine resources surveys in Nigeria. In NISORS (ed) Application \& Remote Sensing Techniques in Nigeria. PgsIlesa Diocese Printing Press Limited

7. Bastiaanssen, W. G. M., Menenti, M., Feddes, R. A., \& Holtslag A. A. M. (1998). A remote sensing surface energy balance algorithm for land (SEBAL), Part 1; formulation. Journal of Hydrology. 212/213, 198-212

8. Curran, P.J. (1992). Principle of remote sensing. New York. Longman

9. Harris, R. (1982). Satellite remote sensing: an introduction. New York/London. Routledge and Kegan Paul.

10. Kumar, N; Yamaa S.S. \& Velmorugan, A. (2015). Application of remote sensing and GIS in natural resource management. Journal of the Andaman Science Association. 20(1), 1 6, ISSN 0970-4183.

11. Liu, Z., Ostrenga, D., Teng, M., \& Kempler, S. (2012). Tropical rainfall measuring mission (TRMM). Precipitation Data and Services for Research and Applications. Bull. Amer. Meteor. Soc., $\quad$ 93, 1317-1325doi: Lttp:dx.doi.org/10.1175/BAMS-D-11-00152.1

12. Melesse A., \& Wang, Y (2007). Imperial surface area dynamics and storm runoff response. In Taylor, C and Francis E(eds). Remote Sensing of impervious surface. Pgs 369-384 CRC Press.
13. Okhimamhe, A.O. (1993). Assessment of environmental impact of dam construction in Nigeria. A case study of Tiga Dam in Kano State. M.Tech. Desertation, Department of Geography. Federal University of Technology, Minna.

14. Okolie, C. J. (2016). Remote sensing and GIS: The Apps for disaster management in Nigeria. Young Surveyors Network (YSN) Nigeria Georeference Magazine. 1, 16-21

15. Okonniyi, O. (1993). Applicable remote sensing system for the Nigerian Coasteric. Nigerian Journal of Remote Sensing. 1(1), 94-101

16. Omali, T. U. (2018). Prospects of satelliteenhanced forest monitoring for Nigeria. International Journal of Scientific and Engineering Research. 9(5), 383-388

17. Patrick, S. (1993). Application of photographic remote sensing system for identifying features of gully erosion in Guinea Savana area of Taraba State, Nigeria journal of Remote Sensing. 1(11), 58-61

18. Seelan, S. K., Laguette, S., Casady, G. M. \& Seielsfad, G. A. (2003). Remote sensing applications for precision agriculture: A learning community approach. Remote Sensing of Environment. 88(1), 157-169.

19. Sun, A. Y. (2013). Predicting groundwater level changes using GRACE data. Water Resources Research. 49(9), 1944-1973. Dol:10.1002/wrcr. 20421.

20. Usman, A. K., Abdullahi, A. H., \& Opara, J. A. (2020). Geographical information system tools and forest resources management in northern Nigeria. Asian Journal of Environmental Science and Technology innovation. 1(2020), 12-20

21. Way, T. (2020). Challenges and opportunities of Nigeria space program. Ohio. AEROSPACE. 